\title{
Integrated lake farming for fish and environmental management in large shallow Chinese lakes: a review
}

\author{
W. Y. B. CHANG Center for Great Lakes and Aquatic Sciences, University of Michigan, \\ Ann Arbor, Michigan, USA and US-China Cooperative Science Program, National \\ Science Foundation, Washington, DC, USA
}

\begin{abstract}
Large shallow lakes in the Pacific Drainage Basin of China are unique aquatic natural resources intensively exploited in recent years for integrated lake farming. This paper presents a general description and major components of this culture method and discusses potential concerns and effects of increased fishery production on aquatic environments.
\end{abstract}

\section{Introduction}

China has 231 lakes larger than $100 \mathrm{~km}^{2}$ with a total area of $59219 \mathrm{~km}^{2}$, representing over $73 \%$ of the total Chinese natural lake area (Chang 1987a). Clusters of these lakes can be found either in the Pacific Drainage Basin or in the Tibet-Qinhai highlands. Large lakes in the Tibet-Qinghai highlands are deep, and more than $50 \%$ of them are saline with temperatures below freezing for more than $4-5$ months a year. This area is sparsely populated, predominantly by minority peoples who do not consume fish due to cultural and religious practices (Chang 1987a). The natural and social environment is not conducive to the development of fish culture in this area. Consequently, little or no aquaculture development is found in this region of China. In contrast, the lakes situated in the Pacific Drainage Basin are shallow, most of them being less than $5 \mathrm{~m}$ deep. Formed as a result of river impacts, they are rich in nutrients with high organic inputs. Average annual temperature in this area is around $13-16^{\circ} \mathrm{C}$. Snow occurs occasionally in January and February. Ice formations are found at the edge of the lakes, but deep freezes are not frequent in this region. Historically, this area has been an agricultural and aquacultural centre for more than 3000 years, and is home to more than $95 \%$ of the Chinese population (Yu, Yuan \& Mao 1987a).

Potential increases in fish production from these lakes can be great. Since the current annual yield of fish captured from the large lakes in the Pacific Drainage Basin is low compared with the production from similar aquaculture systems, the level of production can be substantially increased from these lakes. For example, the catch from Lake Tai is $52 \mathrm{~kg} / \mathrm{ha}$, Lakes Dongting and Hongtze yield $45 \mathrm{~kg} / \mathrm{ha}$, while Lake Chao yields $15-20 \mathrm{~kg} / \mathrm{ha}$. Policy has been established to focus on developing methods to improve the yields of fish and food production from large water bodies so as to meet the increasing demand for fish and other aquatic food items as a result of the increase ( $2 \cdot 5$-fold) in population since 1949 in this region of China. At the same time, natural production of captured fish is decreasing due to pollution, dam construction, and reductions in spawning habitat.

Correspondence: Dr W.Y.B. Chang, Center for Great Lakes and Aquatic Sciences, University of Michigan, Ann Arbor, Michigan 48109, USA. 
Aquaculture is considered to be a major means of meeting the increasing demand for fish, and the increase in pond fish production has been a focus of the government's fish production policy. The per unit pond fish production has nearly doubled since 1975 , with increases particularly noticeable after the implementation of the Chinese government's responsibility system in which fish farmers lease ponds to raise the fish, with the amount above the annual quota set by the government going to the farmers. However, the rate of increase in pond fish production is levelling off, and a major increase in pond fish yields in the traditional fish culture areas would take substantially more investment in both effort and capital. The focus at present is on increasing aquaculture production from Pacific Basin large lakes. Different culture methods have been developed for use in the lake environment, since the integrated culture techniques used in ponds are often not practical in lakes. Among methods used, lake farming shows the greatest promise both ecologically and economically for expanding the fish and other food production. Our objectives are to provide a general description and major components of this culture method, as well as a discussion of potential concerns and effects of increased fishery production on aquatic environments.

\section{Past practices}

In the large bodies of water in China many methods have been used to increase lake fish production. The major approaches used to manage fish in large lakes in China focus on: (1) stocking; (2) establishing and improving spawning environments; (3) regulating fishing periods; (4) regulating water levels using weirs and dams; and (5) controlling fishing boats (Chang 1987a). Since the major goal in managing Chinese lakes is to increase total food production, fish stocked are those species that can use all components of natural food resources in lakes. Types and numbers of fish stocked are based on the lake trophic level; each stocked species has a different diet and uses different parts of the natural resources in lakes (Chang 1987b). The stocking and management concept resembles the polyculture approach used in ponds. The predominant stocked fish are carp species. Grass carp, Ctenopharyngodon idella L., bighead carp, Aristichthy nobilis L., silver carp, Hypophthalmichthys molitrix L., and black carp, Mylopharyngodon piceus L., are the most common of the 16 species stocked (Chang 1987a). This stocking programme has achieved limited success in large lakes in China. Production usually increases slightly after the implementation of such programmes, but the net gain is small. Two major drawbacks have been found to be associated with this method. The number of fish stocked is based on the lake trophic level. Organic fertilization is therefore used to enrich the lake to increase productivity and allow an increased number of fish to be stocked. However, this also results in frequent blue-green algal blooms in summer (Chang \& Ouyang 1988). In addition, aggressive carp stocking programmes, although contributing to higher fish yields, reduce the diversity of indigenous fish species in lakes based on the data collected from small lakes; no data are yet available for large lakes (Liu 1984).

\section{Lake farming}

Fish productivity in Chinese natural lakes is low, rarely exceeding $200 \mathrm{~kg} / \mathrm{ha}$, and unit productivity decreases with increasing lake size. In large Chinese lakes $\left(>500 \mathrm{~km}^{2}\right)$, total fish 
Table 1. Annual net primary production estimates $\left(\mathrm{g} / \mathrm{m}^{2} / \mathrm{year}\right)$ for various vegetation (Modified from Westlake 1963). ${ }^{*}$ indicates the data available from the lake farming project in Lake Tai, China

\begin{tabular}{ll}
\hline Types of vegetation & Production estimates \\
\hline Aquatic plants & \\
Emergent vegetation & 3000 \\
$\quad$ Salt marsh & 4300 \\
$\quad$ Freshwater reedswamp (temperate) & 7500 \\
$\quad$ Freshwater reedswamp (tropical) & 3750 (in 1985)* \\
Aquatic plants used in lake farming & 920 (in 1984)* \\
Water spinach (Ipomaea aquatica forsk) & 600 \\
Trapa & 1700 \\
Submerged vegetation & 200 \\
$\quad$ Attached plants (temperate) & 600 \\
$\quad$ Attached plants (tropical) & 200 \\
Phytoplankton & \\
Freshwater phytoplankton (temperate lake) & \\
Freshwater phytoplankton (enriched lake) & \\
Marine phytoplankton &
\end{tabular}

production rarely exceeds $60 \mathrm{~kg} / \mathrm{ha}$. Low fish productivity in these lakes has been attributed to low primary production. The net primary production by phytoplankton in lakes averages 200 $\mathrm{g} / \mathrm{m}^{2} /$ year (Westlake 1963; Le Cren \& Lowe-McConnell 1980). This level is far lower than the average net production by aquatic plants (Table 1). In order to increase total fish and food production substantially in shallow lakes, harvestable primary production which fish can utilize in lakes must be increased.

Lake farming increases primary production through the selection of suitable aquatic plants that can both use solar energy efficiently and be directly used by man. These aquatic plants are raised for food and fish feed; fish cultured in nearby enclosures are fed with this aquatic vegetation. Rotation between fish enclosures and aquatic plant fields allows plants to use the excess nutrients that are accumulated in the sediment during the fish culture period. The concept of integrated lake farming is similar to integrated land farming (e.g. raising cattle) in which pasture is raised to feed the cattle and the manure from the animals is, in turn, used to fertilize the pasture. The major difference is that the entire operation for integrated lake farming takes place in natural lakes: aquatic plants replace grass as grazing material and fish take over the role of cattle as the cultured animals.

\section{Aquatic plants and herbivorous fish}

The two major components of integrated lake farming are aquatic plants and fish. Suitable aquatic plants and fish species are important to the success of such a system. Aquatic plants are selected for Chinese lake farming based on the characteristics of (1) high efficiency in using solar energy and (2) serving as both food for humans and feeds for fish. High food conversion rates (FCRs) by herbivorous fish and nutrition values of aquatic plants are also considered, but FCRs are mostly used by researchers and are not usually taken into account in the routine decisions regarding the choice of aquatic plants used as fish feed. 
Aquatic plants used in Chinese lake farming are primarily floating or free-floating macrophytes since these types of aquatic plants can use solar energy more efficiently than submerged macrophytes (personal communication with scientists at the Nanjing Institute of Geography and Limnology). Floating macrophytes are also better than phytoplankton at fixing solar energy (Edwards 1980). Areas with dense growths of emergent or floating aquatic plants have been found to have lower frequencies of algal blooms, while heavy growths of phytoplankton effectively shade macrophytes resulting in low or no growth of submerged macrophytes and at times causes die-offs. Herbivorous fish also appear to use floating plants more efficiently than emergent and submerged macrophytes, since floating macrophytes used by herbivorous fish have little lignified tissue. Because the goal of this farming system is to increase food production from a lake environment, an increase in aquatic plant production for human consumption is also a major consideration. Those aquatic plant species which can be used as green leafy vegetables or as supplemental staples (such as Trapa, see description in the later section) are preferred. As a result, aquatic plants selected for this purpose have not been based entirely on fish preference and plant productivity. Nonetheless, species presently cultivated widely in China appear to satisfy both fish preference and high production rates. The high FCR of herbivorous fish feeding on aquatic plants has been considered at times by researchers, who use it as a guide for selecting appropriate species of aquatic plants, but the values of FCR vary considerably and are difficult to apply efficiently. For example, Edwards (1980), using Singh et al.'s 1967 data, found that the FCR for herbivorous fish ranged from 23 to 158 with an average of about 58 . Stott \& Orr (1970) obtained an FCR of 280 with grass carp and lettuce. FCRs ranged from 21 to 81 with an average of 57 for grass carp feeding on duck weed in aquaria (Michewicz, Sutton \& Blackburn 1972). Tal \& Ziv (1978) reported FCRs of 10 and 37 for grass carp feeding on Lemna. Venkatesh \& Shetty (1978) obtained FCRs for grass carp of 27 for the terrestrial Napier grass, 94 for Hydrilla and 128 for Ceratophyllum. The FCRs for plant species used in lake farming in China also vary within a large range from 7 to 65 (Wong, Chen, Bon \& Lin 1987; Yu, Yi, Yi \& Mei 1987b; Hubei Provincial Corporation of Aquaculture and Fisheries, unpublished). Since aquatic plants used to feed fish in lake farming are generally of more than one species, the FCR values shown represent a composite of aquatic plant species. Raising fish in enclosures is still more art than science, and FCRs are largely ignored by aquaculturists. While the FCR is not being used extensively in selecting appropriate aquatic plant species, floating macrophyte species in general have higher protein and lipid content than do emergent and submerged macrophytes (Wetzel 1975) and have been used more efficiently by cultured fish species.

Grass carp is the most important herbivorous fish used in lake farming. More than $40 \%$ of fish stocked in enclosures are generally of this species. Chinese fish culturists use this species of fish as a living manuring machine remineralizing the nutrients contained in the macrophytes, since the gut of the grass carp is short for a herbivore and only $50 \%$ or less of its body length. The vegetation consumed by the grass carp is partially digested, and the faeces of the fish can be either directly consumed as food materials by detrivores or used as fertilizers to enrich the production of natural food such as phytoplankton, zooplankton and benthic organisms. Other herbivorous, planktivorous and detrivorous fishes are also used in this culture system. The percentages of these species stocked usually depend on lake water richness. Bighead carp and silver carp are stocked where both phytoplankton and zooplankton are abundant. In large lakes, however, the percentage of bighead and silver carp is kept under less than $10 \%$, because when food shortages occur in the enclosure, food 
Table 2. Fish stocked in the enclosures in large lakes

\begin{tabular}{lc}
\hline Species & Stocking percentage \\
\hline $\begin{array}{l}\text { Grass carp } \\
\text { (Ctenopharyngodon idella) }\end{array}$ & $50-60 \%$ \\
$\begin{array}{l}\text { Wuchang bream } \\
\text { (Megalobrama amblycephala) }\end{array}$ & $20-30 \%$ \\
$\begin{array}{l}\text { Common carp } \\
\text { (Cyprinus carpio) }\end{array}$ & $10 \%$ \\
$\begin{array}{l}\text { and goldfish (Chinese name - Crucian carp) } \\
\text { (Carassius auratus) }\end{array}$ & \\
$\begin{array}{l}\text { Bighead carp } \\
\text { (Aristichthy nobilis) } \\
\text { and silver carp } \\
\text { (Hypophthalmichthys molitrix) }\end{array}$ & $<5 \%$ \\
\hline
\end{tabular}

limitation has resulted in an absence of or decline in the growth of these species of fish. Benthic feeders such as black carp and common carp, Cyprinus carpio L., are also stocked, but this group is usually not stocked in large lakes with strong current flows because the bottom feeders tend to stir the sediments, which currents can transport from the enclosure area resulting in an area devoid of sediment. Furthermore, in a large lake the benthic productivity within the confinement of an enclosure rarely can keep pace with the feeding pressure from the bottom feeders, and growth rates have been poor compared with other species of fish stocked in this system. However, for many smaller eutrophic lakes, both planktonic and benthic feeders can reach $60 \%$ of the total fish stocked and have been found to utilize the lake's natural food production efficiently.

\section{Successful model}

A successful model of integrated lake farming has been demonstrated in Lake Tai (Ou \& Tu 1987) (Fig. 1), which is the third largest freshwater lake in China, with an area of $2425 \mathrm{~km}^{2}$ (Chang 1987a). This lake is shallow, with an average depth of less than $2 \mathrm{~m}$. An experimental integrated lake farm was established in 1980; currently it occupies an area of about 25 ha and is operated by the Nanjing Institute of Geography and Limnology, Academia Sinica. This integrated production model has substantially increased the food (fish and aquatic plants) production per unit lake surface area. Two components of the lake farming model are described here.

In the integrated aquaculture production system, the average fish production reached $8250 \mathrm{~kg} / \mathrm{ha}$ in 1984 and $15750 \mathrm{~kg} / \mathrm{ha}$ in 1985 . Water quality was generally sound, dissolved oxygen concentration remained high, metabolites such as nitrite and ammonia were low, and reported incidences of infestation of fish with disease were lower than those found in ponds and smaller lakes. Problems that frequently caused major die-offs in pond environments, such as early morning dissolved oxygen deficits and nitrite toxicity (Chang 1986), have not been found in these culture systems. Fish are confined by enclosure nets and are fed aquatic plants collected from the surrounding area or from nearby hydro-agriculture production fields (Fig. 2). Aquatic plants are also raised at the perimeter of the enclosure and are used 


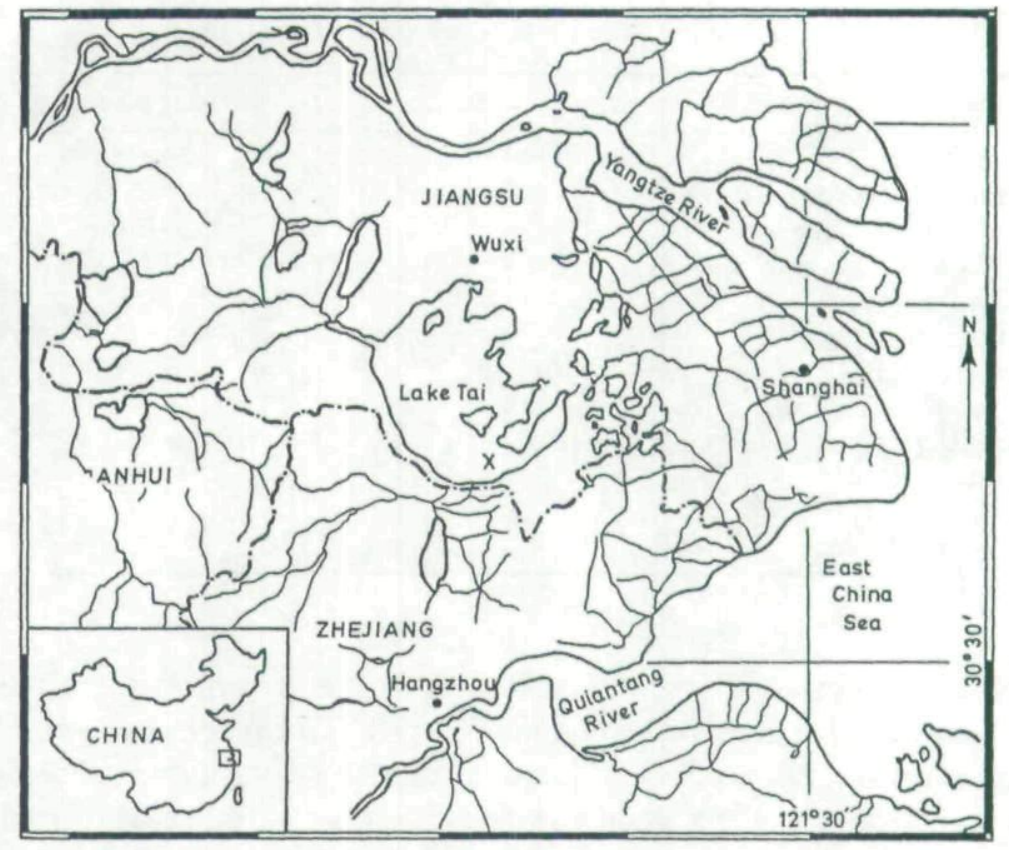

Figure 1. Lake Tai and the integrated lake farming site. $\mathrm{X}$ indicates the lake farming area.

more for reduction of wave impacts than for feed (Fig. 2). Because in these systems the major available feeds are aquatic vegetation, the types of fish cultured differ considerably from those raised in pond culture systems (Chang 1985).

Examples of the types and the percentages of fish stocked in the enclosures in this lake show that the plant consumers, grass carp and Wuchang bream, Megalobrama amblycephala L., are the major stocked species; the percentage of these species in the enclosures can reach $90 \%$. Black carp and common carp, which consume molluscs and benthos respectively, are also stocked, but the number stocked was not higher than $10 \%$ of the total fish stocked in 1984 and 1985. In 1986, these species were not stocked since they resulted in major losses of lake

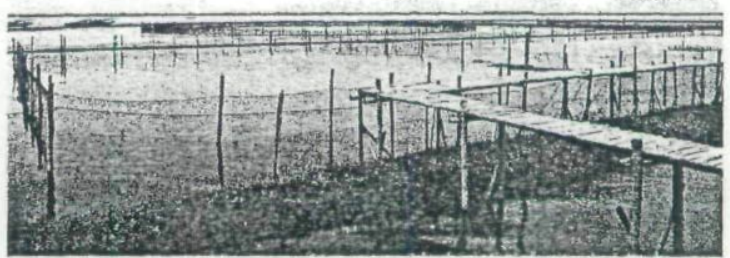

Figure 2. Integrated aquaculture production system. Aquatic plants are raised at the perimeter of the enclosure for feeds and to reduce wave impacts. 


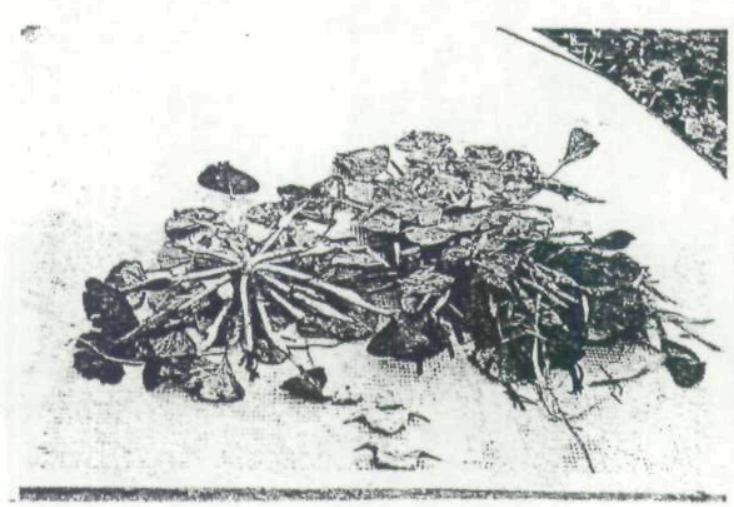

(a)

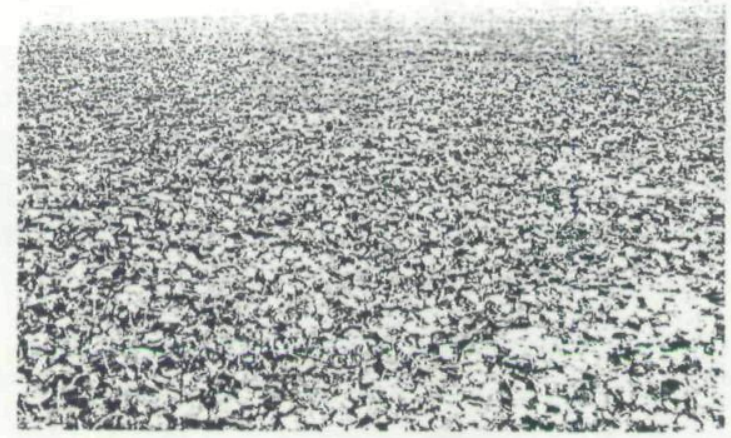

(b)

Figure 3. (a) Trapa natons and (b) the hydro-agriculture production field of Trapa natons.

sediments in the enclosure area. Silver carp and bighead carp showed poor growth in such environments because their diets consist mainly of phytoplankton and zooplankton, and they were unable to find enough food when confined in the enclosures. The stocking number for these two species has been kept very low; in some enclosures none are stocked. The total stocking weight for fish is usually $3750 \mathrm{~kg} / \mathrm{ha}$.

The aquatic plants used in the hydro-agriculture fields are Trapa natons (Fig. 3), Euryale ferox and Ipomaea aquatica forsk (water spinach) (Fig. 4). Brasenia schreberi, Nelumbo nucifera and rice were also raised, but the results were not successful in this environment. In this type of agriculture, seedlings are transplanted from the nursery and grown on growth nets. All successful species used are floating aquatic macrophytes which when living in natural waters are usually restricted to sheltered habitats. In the culture environments, these species are supported by devices made of bamboos and growth nets to station the cultivated aquatic plants in a confined area. The growth net is usually suspended horizontally by bamboo poles to maintain a plane a few centimetres beneath the water surface. Using this approach, the production of Trapa was $9225 \mathrm{~kg} / \mathrm{ha}$ in 1984, and the seed production of Euryale was about $2300 \mathrm{~kg} / \mathrm{ha}$. The annual production of water spinach is remarkable, reaching $37500 \mathrm{~kg} / \mathrm{ha}$ in 1985 ; this is the most promising plant for this type of production system.

The aquatic plants for hydro-agriculture production not only provide fish feed, but also food for humans. Trapa pods have long been a major diet item in many parts of China and are 


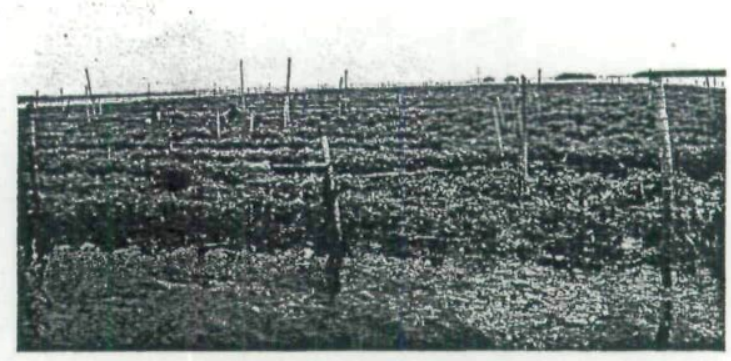

Figure 4. Hydro-agriculture production field of water spinach, Ipomaea aquatica forsk.

sold in the free markets. Water spinach is an important green vegetable for the Chinese; while the green leafy part is consumed by man, the remaining portion can nearly all be used by grass carp. Rotation in culture sites between fish enclosures and hydro-agriculture experimental fields can reduce the accumulation of nutrients in lake sediment and of floating detritus after harvesting aquatic plants. Rooted aquatic plants can use the nutrients accumulated by culturing fish as fertilizer, and fish can feed on the aquatic plant remnants.

\section{Major production concerns}

Lake farming and enclosure aquaculture have become popular in recent years in the Chinese lakes and waterways. The area engaged in such operation has increased from merely an experimental zone of less than 1 ha in 1982 to more than 1300 ha in 1986 in Lake Tai (Wong et al., 1987; Xu \& Shen, unpublished) and in some provinces, more than 10-20-fold increases in lake area devoted to this type of aquaculture activity have been reported (Zhong 1986). However, fish production levels from this type of system vary widely from $500 \mathrm{~kg} / \mathrm{ha}$ to more than $10000 \mathrm{~kg} / \mathrm{ha}$. Several major problems were consistently reported by the practitioners of this type of culture system. Predation by piscivorous fish, which enter the enclosures from the open lake during the culture period or were there when the enclosures were constructed, is mentioned most frequently (Liu, unpublished). The eradication of piscivorous fish from the enclosures in a lake is a major task and is much more difficult than in a pond environment. Fish escaping through nets is also reported; this is most frequent during major storms when the net may be torn. Accumulation of dead fish at the enclosure perimeters can contribute to fish escaping since water mice and other animals, while preying on dead fish, frequently cause serious damage to the net, resulting in major losses of fish.

Harvesting the fish from the enclosures is also a prime concern. In pond environments, water can be drained to facilitate harvest. Draining is impossible in a lake enclosure, and effort required to harvest fish from the enclosures is therefore substantial and fish re-capture rates can be low, especially if large numbers of bottom-feeders are stocked. This type of culture system also requires a good deal of manpower to maintain and repair the enclosure, provide feed to the fish, and harvest the fish. For example, an average enclosure which is usually stocked with $2000 \mathrm{~kg} / \mathrm{ha}$ of herbivorous fish requires a daily collection of $2000 \mathrm{~kg} / \mathrm{ha}$ of 
aquatic plants to feed the fish in the enclosures. The surplus in manpower in China and many third-world nations not only makes this system profitable, but even produces a profit margin which is high compared to other types of farming activities.

Intense lake farming in aquatic environments

\section{Effects on dissolved oxygen concentration}

The growth of dense aquatic vegetation frequently results in major fluctuations of diurnal dissolved oxygen (DO) and carbon dioxide concentrations in water. The characteristics of these fluctuations differ based on the type and density of the aquatic plants cultured. For the submerged macrophytes, the DO concentration in the area with dense growth is lower than that of the open water during the night due to heavy respiration (Edwards 1980). During the day, DO concentration in the upper depths (particularly the layer above the submerged macrophytes where light conditions are adequate) can be as high as in the open water. In the lower depths of the aquatic macrophytes, however, the oxygen concentration can be much lower than in the open water at the same depth. Dissolved oxygen under floating or emergent aquatic plants, which are the predominant types of aquatic vegetation used in the Chinese integrated lake farming, can be low. Schelpe (1961) reported that DO levels below salvinin mats are $0.64 \mathrm{mg} / \mathrm{l}$ near the surface of the plants and $0.66 \mathrm{mg} / \mathrm{l}$ at the depth of $1 \mathrm{~m}$, when in nearby open lake areas, the surface and $1-\mathrm{m}$ depths were $4.4 \mathrm{mg} / \mathrm{l}$ and $6.9 \mathrm{mg} / \mathrm{l}$ respectively. Ashton \& Walmsley (1976) indicated the water beneath multilayered mats of Azolla filculoides was anaerobic and that fish were not able to survive there. However, the degree of deoxygenation under floating and emergent macrophytes is by no means uniform. Rather, it is related to mat thickness, coverage, and length of time the mats had not been disturbed. For large lake environments, major current circulation needs to be considered when discussing DO concentration. This current is strong and formed as a result of microcyclic climate which produces lakeward wind flow during day and landward flow at night; it can substantially mix the water under heavy aquatic weed beds. The DO concentration under aquatic plants is inversely related to the area of coverage. The degree of deoxygenation under cultured aquatic plants can be reduced when vegetation plot size is properly considered with the current flow under the mats.

\section{Effects on $\mathrm{CO}_{2}$ and fish}

Deoxygenation in dense growths of macrophyte beds also affects free $\mathrm{CO}_{2}$ concentration in water, which in turn influences fish survival. When photosynthesis is high, DO is high while free $\mathrm{CO}_{2}$ is low. Beneath dense growths of macrophytes, this relationship is reversed so that $\mathrm{DO}$ is generally very low and free $\mathrm{CO}_{2}$ is abnormally high. For example, Krishnamoorthi (1976) reported that the $\mathrm{DO}$ level was near zero and free $\mathrm{CO}_{2}$ varied from 60 to $100 \mathrm{mg} / \mathrm{l}$. This high $\mathrm{CO}_{2}$ can reduce the affinity of freshwater fish blood for oxygen (Alabaster \& Stott 1967; Edwards 1980); as a result, fish can be asphyxiated at a higher concentration of DO when high $\mathrm{CO}_{2}$ is present.

Substantial reductions in natural fish populations have been found in water which is extensively covered by macrophytes. The fish die predominantly of asphyxiation as 
deoxygenation is serious. In a large lake where the littoral zone is small in proportion to open water, DO problems are primarily due to algal respiration and degradation, and the reduction in number of natural fish due to increases in culture of aquatic plants has not been noticeable. However, this situation may change rapidly if culture of aquatic vegetation for lake farming occupies a substantial part of the lake area. Anoxic conditions may develop in both the littoral and the deeper parts of the open water resulting in a large reduction in fish populations.

\section{Effects of enclosed fish}

\section{Grazing}

In a natural lake, loss of aquatic plants due to grazing is usually slight, and ranges from about 0.5 to $8 \%$ of the total aquatic vegetation (Wetzel 1975). Under most circumstances, most macrophyte production is consumed by bacterial and fungal degradation as the plant population declines. However, in a lake with an intensive culture of macrophytes for lake farming, grazing by herbivorous fish is the major consumption route. As a result, the remineralization of nutrients from macrophyte does not occur seasonally during the scenace or die-off of the plants, but continuously as the herbivorous fish consume the aquatic plants and then release the nutrients to the water. Since the major herbivorous fish used in the culture is grass carp, which has a short gut and is an inefficient user of aquatic plants, the release of nutrients to water is large and continuous during the culture period (Pearl River Fisheries Research Institute 1982). The inorganic nutrients from this enrichment into the water column provide a relatively constant supply of nutrient for phytoplankton growth in the open water area of a lake where shading is not a major problem. Dissolved organic matter released by fish forms nitrogen-rich detritus, which can be an important food source for detrivores in lakes.

\section{Reduction in sediment resuspension}

Most lakes in the Pacific Drainage Basin are shallow, and resuspension of sediment has been one of the major sources of nutrient input to the water column (Chang 1987a). Therefore, control of nutrient input in many cases has not resulted in major improvement in eutrophication conditions in these lakes. Areas with dense growths of aquatic vegetation have reduced sediment resuspension and nutrient recycling from sediment to the water column. In large lakes, lakewide circulation is strong, and sediment is not only resuspended, but also transported by currents. An area with substantial growth of vegetation has been found to stabilize the sediment and reduce both sediment resuspension and transport. Furthermore, harvesting of macrophytes for human and land animal consumption removes nutrients from the lakes. A combination of these activities has been shown to improve eutrophication conditions and to reduce unwanted algal blooms.

\section{Outlook}

Lake farming has great potential for playing a major role in increasing food production from 
large bodies of waters, which has had limited success in contributing to aquatic food and fish production in China. Integrated lake farming extends land agriculture to aquatic systems and provides a more efficient way of using and managing large, shallow, under-utilized water bodies of the world. Successful examples of applying this system in increasing aquatic food and fish production have been demonstrated in China, where more than $100 \%$ net increases in profit have been reported by many state fish farms. This farming technique has gained considerable popularity in recent years in the lake districts of China and an increasing trend is expected to continue.

Profit for this type of culture is high, but the risk is also high compared with pond culture. Therefore, the most immediate concern is to reduce the risk of such an operation, including damage to enclosure nets, invasion of phagous fish, diseases, pests, and, most recently, industrial pollution. After 1980, the new economic initiative provided strong impetus for large increases in both agriculture and industrial production in China. The growth and expansion of the industrial sector in China have resulted in increased industrial pollution in rivers, waterways and lakes, where lake farming takes place. These pollutants can result in retarded growth or death of fish and low yields of aquatic macrophytes, and once these pollutants enter the aquatic food chain they can result in health problems for human populations. This type of pollution will have an increasing impact on aquaculture in the rivers, waterways and lakes. No major control of this pollution has been implemented, and it is expected that this problem will become more serious as industrial development continues. Another problem causing increasing concern is the pest and disease problem. As lake farming becomes more intensive, disease and pest problems are likely to occur more frequently. Increased incidences of major disease outbreaks have been reported in lake enclosures, reflecting the potential risk of this type of culture. Additional research is needed better to control the outbreak of disease and pests.

As for lake management, integrated lake farming can be a useful method for reducing the effects of eutrophication in large, shallow lakes. Because shallow lakes are easily mixed by wind, particularly the large shallow $(<3 \mathrm{~m})$ lakes in China's Pacific Basin where wind and current mix the water daily during the ice free period, the sediment is frequently resuspended when wind and current are strong. This causes the nutrients stored in the sediment to be released into the water column, producing frequent algal blooms. The extensive planting of aquatic macrophytes for lake farming stabilizes the sediment and reduces nutrient resuspension. The result is a reduction in the frequency of blue-green algal blooms in areas where extensive aquatic vegetation is planted. As a result of these potential benefits in controlling eutrophication, a major plan has been drafted for using this method to improve the water quality of Lake Tai in Jiangsu Province. It has been estimated that an area of $50 \mathrm{~km}^{2}$ dedicated to integrated lake farming in Lake Tai can yield as much or more than the total annual fish production from the entire lake (total area $=2425 \mathrm{~km}^{2}, 52-60 \mathrm{~kg} / \mathrm{ha}$ ), and can reduce the resuspension of nutrients from the sediments. Furthermore, the planting of these macrophytes creates areas of vegetation which serve as refuges for young fish and spawning grounds for indigenous fish species. Lake farming has great potential for becoming a popular choice for managing large shallow lakes.

\section{Acknowledgments}

This study was supported by the UM Rackham Graduate School's Faculty Grant Program to 
Augment International Academic Partnership, and by a grant (no. DAN-4023-G-SS-706600) from the Pond Dynamics/Aquaculture Collaborative Research Support Program (CRSP), Agency for International Development. Matching funds for the grant were provided by the Office of the Vice President for Research, the University of Michigan. The comments and suggestions provided by Dr David Jude are gratefully acknowledged.

\section{References}

Alabaster J.S. \& Stott B. (1967) Grass carp (Ctenopharyngodon idella) for aquatic weed control. Proceedings of European Weed Research Council, International Symposium on Aquatic Weeds 2, 123-126.

Ashton R.J. \& Walmsley R.D. (1976) The aquatic fern Azolla and its Anabaena symbiont. Endeavour 35, $39-43$.

Chang W.Y.B. (1985) Pond fish culture in the Pearl River Delta. Aquaculture Magazine 11, 45-46.

Chang W.Y.B. (1986) Practical methods for treating fish during oxygen stress in ponds. Aquaculture Magazine 12, $20-21$.

Chang W.Y.B. (1987a) Large lakes of China. Journal of Great Lakes Research 13, 235-249.

Chang W.Y.B. (1987b) Fish culture in China. Fisheries 12, 11-15.

Chang W.Y.B. \& Ouyang H. (1988) Dynamics of dissolved oxygen and vertical circulation in fish ponds. Aquaculture 74, 263-276.

Edwards P. (1980) Food Potential of Aquatic Macrophytes. ICLARM Studies and Review 5.

Hubei Provincial Corporation of Aquaculture and Fisheries (Unpublished) Enclosure aquaculture in Michan Lake, Hubei province, China. Hubei Provincial Corporation of Aquaculture and Fisheries Report (HPCAF).

Krishnamoorthi K.P. (1976) Aquatic plants in relation to public health aspects in Nagpur District and elsewhere. In: Aquatic Weeds in South East Asia (ed. by C.K. Varshney \& J. Rzoska), pp. 162-166. Dr W. Junk B.V., The Hague.

Le Cren E.D. \& Lowe-McConnell R.H. (1980) The Functioning of Freshwater Ecosystems. Cambridge University Press. International Programme 22.

Liu A.M. (Unpublished) A brief review of aquaculture in a large lake in Wuxi, China. National Tai Tung Fish Farm.

Liu J.K. (1984) Tong Lakes. In: Data Book of World Lakes. Proceedings of SHIGA Conference 84 on Conservation and Management of World Lake Environment.

Michewicz J.E., Sutton D.L. \& Blackburn R.D. (1972) Water quality of small enclosures stocked with white amur. Hyacinth Control Journal 10, 22-25.

Ou Y. \& Tu Q. (1987) Brief introduction to a preliminary experiment in water agriculture of East Taihu Lake. Nanjing Institute of Geography Report, Academia Sinica.

Pearl River Fisheries Research Institute (1982) Pond Fish Culture in China (A Manual). Pearl River Fisheries Research Institute, Chinese Academy of Fisheries Science, Guangzhou, China.

Schelpe E.A.C.L.E. (1961) The ecology of Salvinia auriculata and associated vegetation on Kariba Lake. Journal of South African Botany 27, 181-187.

Singh S.B., Sukumaren K.K., Pillai K.K. \& Chakrabarti P.C. (1967) Observations on the efficacy of grass carp in controlling and utilizing aquatic weeds in ponds in India. Proceedings of Indo-Pacific Fisheries Council 12, 220-235.

Stott B. \& Orr L.D. (1970) Estimating the amount of aquatic weed consumed by grass carp. Progressive Fish-Culturist 32, 51-54.

Tal S. \& Ziv I. (1978) Culture of exotic species in Israel. Bamidgeh 30, 3-11.

Venkatesh R. \& Shetty H.P.C. (1978) Studies on the growth rate of the grass carp Ctenopharyngodon idella (Valenciennes) fed on two aquatic weeds and a terrestrial grass. Aquaculture 13, 45-53.

Westlake D.F. (1963) Comparisons of plant productivity. Biological Review 38, 385-425.

Wetzel R.G. (1975) Limnology. Saunders Company, Philadelphia.

Wong B.Y., Chen W.H., Bon C.P. \& Lin T.Z. (1987) Enclosure aquaculture in Wuli Bay, Lake Tai. Freshwater Fisheries (China) 3, 30-32.

Xu P.C. \& Shen P.Z. (Unpublished) Techniques for enhancing enclosure aquaculture in lakes. Freshwater Aquaculture Center, China.

Yu W.T., Yuan C.L. \& Mao W.G. (1987a) Environmental Protection in China. Scientific Publisher, Beijing, China.

Yu F.M., Yi G.C., Yi Z.G. \& Mei G.F. (1987b) Technical Report I and II on enclosure aquaculture. Hunan Provincial Fisheries Research Institute Report: 1-12.

Zhong C.M. (1986) Importance of enclosure aquaculture in the development of lake fishery. Yiyang Region Agriculture Bureau Report: 1-7, Hunan Province, China. 
This document is a scanned copy of a printed document. No warranty is given about the accuracy of the copy. Users should refer to the original published version of the material. 